\title{
Identification of glucan-mannoprotein complexes in the cell wall of Candida albicans using a monoclonal antibody that reacts with a $(1,6)$ - $\beta$-glucan epitope
}

\author{
Raquel Sanjuán, Jesús Zueco, Roberto Stock, † Jaime Font de Mora and \\ Rafael Sentandreu
}

Departamento de Microbiologia, Facultat de Farmàcia, Universitat de València, Avgda. Vicente Andres Estelles $s / n, 46100$ Burjassot (València), Spain

\author{
Author for correspondence: R. Sentandreu. Tel: +3463864299 . Fax: +3463864682 . \\ e-mail: rafael.sentandreu@uv.es
}

\begin{abstract}
The use of a novel monoclonal antibody (mAb) that reacts with $(1,6)-\beta$-glucan has permitted the study of the different covalent linkages between glucan and mannoproteins in the cell wall of Candida albicans. The MAb JRR1 was originally raised by immunization with Zymolyase extracts from $C$. albicans cell walls, but it soon became apparent that it reacted with a $(1,6)$ - $\beta$-glucan epitope. By using this antibody, we show the existence of glucan-mannoprotein complexes between the $(1,6)-\beta$-glucan epitope recognized by the antibody and cell wall mannoproteins. The topology of the $(1,6)-\beta$-glucan in the cell wall of $C$. albicans has also been studied.
\end{abstract}

Keywords: Candida albicans, cell wall, monoclonal antibody, $(1,6)-\beta$-glucan assembly and topology

\section{INTRODUCTION}

The components of the walls of Candida albicans are $\beta$ glucans, chitin and mannoproteins, and although some aspects of their biosynthesis have been studied, the molecular organization of the cell walls is largely unknown, owing to the difficulties in identifying individual macromolecules. Glucans and chitin form a skeleton for the mannoproteins, which are localized mainly at the outer surface, although they are also found throughout the cell wall structure (Elorza et al., 1989; Calderone \& Braun, 1991; Shepherd \& Gopal, 1993; Klis, 1994). Several chitin-synthase-coding genes have been cloned from both yeast and mycelial gene libraries of $C$. albicans (Chen-Wu et al., 1992), and wheat germ agglutinin has been used to show that chitin, although concentrated in the cross-walls between mother and daughter cells, is also randomly distributed throughout the whole cell wall (Marcilla et al., 1991). In the case of Saccharomyces cerevisiae mannoproteins, biochemical (Schekman \& Novick, 1982) and genetic (Ballou, 1990; Schreuder et al., 1993) approaches have facilitated the study of their synthesis and secretion, whilst the distribution of mannoproteins in

\footnotetext{
† Present address: Instituto de Parasitologia, 'Lopez Neyra', C/Ventanilla 11, 18001-Granada, Spain.

Abbreviations: ConA, concanavalin A; mAb, monoclonal antibody.
}

the walls of $C$. albicans has been studied using concanavalin A (ConA) lectin (Marcilla et al., 1991).

The study of the cytological distribution of glucans has been hampered by lack of specific lectins or antibodies, as no lectin reacts exclusively with glucans and because glucans are not immunogenic by themselves. Only when coupled to a protein does a small oligosaccharide, such as laminaribiose (Horisberger \& Rouvet-Vauthey, 1985) or pustulan (Montijn et al., 1994), become immunogenic. Nonetheless, the biosynthesis of both $(1,3)-\beta$ - and $(1,6)-\beta$ glucans has been studied in $S$. cerevisiae using biochemical and genetic methods. In the case of $(1,3)-\beta$-glucan, its formation takes place at the plasma membrane (Shematek et al., 1980). (1,6)- $\beta$-Glucan synthesis is apparently initiated at the endoplasmic reticulum and the nascent molecules are elongated along the secretory pathway (Roemer et al., 1993).

All cell wall components, once secreted or extruded from the plasma membrane, could interact to produce different types of bonds, including hydrophobic, ionic and covalent bonds which give rise to the final molecular organization of the cell wall. Glucan and chitin are connected by covalent bridges in Schizophylum commune (Sonnenberg et al., 1982; Wessels et al., 1983); linkages between glucan and mannoproteins have been reported in $S$. cerevisiae (Van Rinsum et al., 1991; Montijn et al., 1994). In C. 
albicans, linkages between a $(1,6)-\beta$-glucan and chitin (Surarit et al., 1988), and between mannoproteins and both glucans and chitin (Elorza et al., 1985; Marcilla et al., 1991, 1993), have also been described.

The development of monoclonal antibodies ( $\mathrm{mAbs}$ ) has opened new ways to identify specific molecules (Casanova et al., 1989; Sundstrom et al., 1986) and to investigate the molecular processes involved in their formation, as well as the types of bridges connecting them in the fungal cell walls (Elorza et al., 1989; Marcilla et al., 1991; Torosantucci et al., 1990; Trinel et al., 1992).

In this paper we present what to our knowledge is the first mAb (JRR1) that reacts with a $(1,6)-\beta$-glucan epitope, although a polyclonal antibody reacting against the same epitope has recently been described (Montijn et al., 1994). Using this $\mathrm{mAb}$ we have studied the linkages connecting $(1,6)-\beta$-glucan to the mannoproteins, the presence of $(1,6)$ $\beta$-glucan in the mannoproteins secreted by regenerating protoplasts, and also the topology of the distribution of $(1,6)-\beta$-glucan in the cell walls of $C$. albicans.

\section{METHODS}

Strains and conditions of growth. Candida albicans ATCC 26555 serotype A was grown according to the method of Elorza et al. (1989). Cells incubated at $28^{\circ} \mathrm{C}$ in Lee medium (Lee $e t$ al., 1975) were collected after $12-18 \mathrm{~h}$, when they were at the exponential growth phase. For the formation of mycelium, yeast cells stored in water at $4{ }^{\circ} \mathrm{C}$ for $24-42 \mathrm{~h}$ were incubated at $37^{\circ} \mathrm{C}$ for $6 \mathrm{~h}$ in Lee medium and then collected. To analyse the effect of tunicamycin on the localization of the $\mathrm{mAb} J \mathrm{RR} 1$ epitope in the cell surface, cells were grown in Lee medium at 28 and $37^{\circ} \mathrm{C}$ for $2 \mathrm{~h}$, and then the antibiotic was added at a concentration of $20 \mu \mathrm{g} \mathrm{ml}^{-1}$. After $4 \mathrm{~h}$ incubation cells were harvested and indirect immunofluorescence was performed.

Preparation of different materials from cell walls. Cell walls were obtained as described by Marcilla et al. (1993) and extracted with $2 \%(\mathrm{w} / \mathrm{v}) \mathrm{SDS}$ for $10 \mathrm{~min}$ at $100{ }^{\circ} \mathrm{C}$ to remove noncovalently-retained molecules.

The wall material was solubilized by Zymolyase $20 \mathrm{~T}$, and mannan from the walls of different fungi was obtained as described by Marcilla et al. (1993). Walls previously treated with $2 \%$ SDS from $30 \mathrm{mg}$ (dry wt) of cells were suspended in $1 \mathrm{mM}$ PMSF containing Zymolyase $20 \mathrm{~T}\left(1 \mathrm{mg} \mathrm{ml}^{-1}\right)$ and incubated at $30^{\circ} \mathrm{C}$ for $3 \mathrm{~h}$. The suspension was then centrifuged $(1200 \mathrm{~g}$, $15 \mathrm{~min}$ ), the wall residues discarded and the solubilized material concentrated by lyophilization.

In order to obtain mannan preparations, walls previously treated with $2 \%$ SDS were boiled in $2 \%(\mathrm{w} / \mathrm{v}) \mathrm{NaOH}$ for $2 \mathrm{~h}$. Solubilized mannan was purified by precipitation with Fehling solution (Edwards, 1965), washed with hot water and redissolved by addition of $0.5 \mathrm{M} \mathrm{HCl}$ until the blue colour disappeared. The mannan was precipitated by $75 \%(\mathrm{v} / \mathrm{v})$ ethanol in water at $20^{\circ} \mathrm{C}$ for $18 \mathrm{~h}$ and after washing twice with $75 \%$ ethanol, it was dissolved in distilled water.

The total sugar content of the different materials was determined by the method of Dubois et al. (1956), and the total protein content was determined by the Lowry method.

Preparation of mannan from mannoproteins secreted by regenerating spheroplasts. Spheroplasts of $C$. albicans were obtained and regenerated as previously described (Elorza $e t$ al.,
1983). After $6 \mathrm{~h}$ incubation at $28^{\circ} \mathrm{C}$, the regenerating medium was separated from cells by centrifugation. The medium which contained the mannoproteins secreted by the spheroplasts was dialysed against distilled water at $4{ }^{\circ} \mathrm{C}$ and concentrated by lyophilization. To obtain the mannan, this concentrated material was treated with $2 \mathrm{M} \mathrm{NaOH}$ for $2 \mathrm{~h}$ at $100^{\circ} \mathrm{C}$, and then processed in the same way as described above for the material extracted from cell walls.

Indirect immunofluorescence for the detection of cell surface antigens. The immunofluorescence assay was performed basically as described by Casanova et al. (1989). Cells were washed three times with $\mathrm{PBS}(0 \cdot 145 \mathrm{M} \mathrm{NaCl}, 0 \cdot 15 \mathrm{M}$ sodium phosphate) and incubated at $37^{\circ} \mathrm{C}$ for $1 \mathrm{~h}$ with the appropriate dilution in PBS of the antibodies $(1: 25$ for $\mathrm{mAb}$ JRR1 and $1: 50$ for $\mathrm{mAb}$ 1B12). After three washes with PBS the cells were incubated with fluorescein-isothiocyanate-conjugated goat anti-mouse IgG (Boehringer Mannheim), diluted $1: 10$ in PBS at $37^{\circ} \mathrm{C}$ for $1 \mathrm{~h}$. After three washes with PBS the cells were then examined with a Zeiss Photo Microscope III equipped for epifluorescence. Fluorescence was dependent on the reaction of the cells with the $\mathrm{mAbs}$, since no fluorescence was detected when the cells were incubated with the second antibody only.

ConA-affinity chromatography. The mannan or Zymolyase extract obtained from yeast walls of $C$. albicans was dissolved in $40 \mathrm{mM}$ Tris/ $\mathrm{HCl}, \mathrm{pH} 7 \cdot 4$, containing $1 \mathrm{mM} \mathrm{CaCl}, 1 \mathrm{mM}$ $\mathrm{MgCl}_{2}, 1 \mathrm{mM} \mathrm{MnCl}$ and $0.5 \mathrm{M} \mathrm{NaCl}$ (ConA buffer) and applied on a ConA-Sepharose 4B (Pharmacia) column, equilibrated with the same buffer. The column was washed with three bed volumes of ConA buffer, and the material bound by the ConA was eluted with ConA buffer containing $0.5 \mathrm{M}$ methyl $\alpha$-Dmannopyranoside. The non-bound and the eluted mannan or Zymolyase-extracted fractions were desalted by dialysis against distilled water and lyophilized.

Paper chromatography. The mannan fractions were hydrolysed in $4 \mathrm{M} \mathrm{HCl}$ for $4 \mathrm{~h}$ at $105^{\circ} \mathrm{C}$ and lyophilized to eliminate the $\mathrm{HCl}$. Partial acid hydrolysis was carried out in $2 \mathrm{M} \mathrm{HCl}$ for $2 \mathrm{~h}$ followed by lyophilization. Sugars were separated by descending paper chromatography in ethyl acetate/pyridine/ water $(8: 2: 1$, by vol.). After $54 \mathrm{~h}$, the chromatography paper was developed by silver staining.

Production of mAbs. For the production of $m A b$ JRR1, female $\mathrm{BALB} / \mathrm{c}$ mice were inoculated intraperitoneally (i.p.) with $100 \mu \mathrm{l}(50 \mu \mathrm{g}$ protein) Zymolyase-extracted material from $C$. albicans cell walls in PBS, emulsified with an equal volume of complete Freund's adjuvant. Two weeks later the mice received a booster i.p. injection with the same amount of antigen emulsified with incomplete Freund's adjuvant. One week after this immunization the mice were tail-bled and the sera tested for anti-antigen antibody titre by ELISA. Selected animals received two boosts with the same immunogen, and $3 \mathrm{~d}$ following the last injection, the splenocytes from the immunized mouse and P3-X63/Ag 8.653 murine myeloma cells were fused at a 5:1 ratio using PEG 1.500 as the fusing agent. Cell fusion and selection of hybrids were performed as described by Galfre \& Milstein (1981). The fused cells were distributed in 96-well culture plates at an approximate density of $10^{5}$ cells per well. Ten days after the fusion, the culture supernatants were screened for the presence of antibodies against the antigen (Zymolyaseextracted material from $C$. albicans cell walls) by indirect ELISA. Positive hybridomas were cloned by limiting dilution in 96-well Nunclon plates containing feeder cells. Ten days later, supernatants from growing hybridomas were tested by ELISA and hybridomas from positive wells were subcloned. Ascitic fluid was obtained as described by Hoogenraad \& Wraight (1986). mAbs were purified from ascites by precipitation with $50 \%$ 
(w/v) ammonium sulfate. The immunoglobulin class of antibodies determined with a Mouse Monoclonal Antibody Isotyping Kit (Sigma Immuno Chemicals).

Preparation of pustulan. Pustulan was prepared from the lichen Umbilicaria papullosa according to the method of Lindberg \& McPherson (1954), and modified by Reese et al. (1962). The lichen $(100 \mathrm{~g})$ (Calbiochem) was pulverized and boiled for $15 \mathrm{~min}$ in $500 \mathrm{ml} 0.165 \mathrm{M} \mathrm{H}_{2} \mathrm{SO}_{4}$. After this, ethanol was added until the concentration reached $13 \%(\mathrm{v} / \mathrm{v})$ and then the mixture was centrifuged. The supernatant was collected and ethanol was added until reaching $50 \%(\mathrm{v} / \mathrm{v})$; after centrifuging, the white pellet was washed three times with acetone and dried at $37^{\circ} \mathrm{C}$.

ELISA. These assays were performed as described previously by Voller \& Bidwell (1986) with the following modifications. Nunc-Immunoplate I (A/S Nunc) plates were coated with appropriate amounts of different materials and incubated overnight at $4{ }^{\circ} \mathrm{C}$. In the case of mannan, previous experiments have shown that similar results were obtained either when directly coating with the polymer or after initial coating with the antibody (Marcilla et al., 1993). The wells were rinsed three times with $0.05 \%$ Tween 20 in Tris-buffered saline (TBS) (TBST) then filled with $3 \%(\mathrm{w} / \mathrm{v}) \mathrm{BSA}$ in TBS and incubated for $2 \mathrm{~h}$ at $37^{\circ} \mathrm{C}$. Each plate was washed three times with TBST. The appropriate diluted antibody $1: 1000$ for $\mathrm{mAb}$ JRR1 and $1: 8000$ for $\mathrm{mAb} 1 \mathrm{~B} 12)$ in TBST was added to the wells and the plate incubated at $37^{\circ} \mathrm{C}$ for $2 \mathrm{~h}$. After washing three times with TBST, an alkaline-phosphatase-conjugated goat anti-mouse immunoglobulin (Bio-Rad) was diluted 1:500 in TBST and $50 \mu \mathrm{l}$ was added to the wells. After $2 \mathrm{~h}$ at $37^{\circ} \mathrm{C}$ they were rinsed again and the substrate mixture ( $50 \mu \mathrm{l} p$-nitro-phenylphosphate, $1 \mathrm{mg} \mathrm{ml}^{-1}$, in diethanolamine buffer) was added to each well and developed for $45 \mathrm{~min}$. The colour intensity was read at $405 \mathrm{~nm}$ with a plate reader (Titertek Multiscan Plus MKII; Labsystems).

The antigen competition ELISA was carried out on plates coated with $10 \mu \mathrm{g}$ (valued as sugar), per well, of material solubilized by Zymolyase from $C$. albicans yeast cell walls. The mAb JRR1 diluted 1:10000 was incubated with laminarin (Sigma) (a 1,3- $\beta$-glucose polymer) or pustulan (a $1,6-\beta$-glucose polymer) solutions of different concentrations for $2 \mathrm{~h}$ at $37^{\circ} \mathrm{C}$ before being added to the wells of the ELISA plates

\section{RESULTS}

\section{Characterization of the MAb JRR1}

JRR1 was raised by injecting mice with Zymolyase extracts from $C$. albicans cell walls, but its reactivity with similar extracts from different fungi, together with its property of being immunoadsorbed by glucan (data not shown), led us to think that the epitope recognized could be either $(1,3)-\beta$ - or $(1,6)-\beta$-glucan. To determine which of the two epitopes was recognized by the $\mathrm{mAb}$, a competition ELISA assay between pustulan or laminarin and an antigen recognized by the $m A b$ was devised. The $m A b$ diluted 1:10000 was pre-incubated with increasing amounts of either laminarin or pustulan for $2 \mathrm{~h}$ at $37^{\circ} \mathrm{C}$, to promote formation of the antigen-antibody complexes. The free $\mathrm{mAb}$ present in the solutions after the preincubation was titrated by ELISA, coating the wells of the microtitre plates with Zymolyase extracts. When the preincubation had taken place at low concentration of the polysaccharides, no decrease of $\mathrm{mAb}$ titre was detected, but when pustulan was present at a concentration of $0 \cdot 11 \mathrm{mg} \mathrm{ml}^{-1}$ and higher, significant drops in $\mathrm{mAb}$ titre

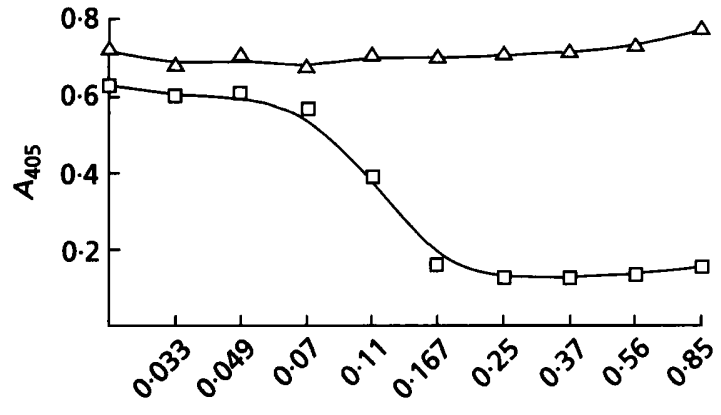

Pustulan/laminarin concn ( $\mathrm{mg} \mathrm{ml} \mathrm{m}^{-1}$ )

Fig. 1. Laminarin $(\Delta)$ and pustulan $(\square)$ competition assay. mAb JRR1 was preincubated with increasing concentrations of laminarin or pustulan solutions and used afterwards to detect the JRR1 epitopes present in the Zymolyase extract from $C$. albicans yeast cell walls. Wells were coated with $10 \mu \mathrm{g}$ (valued as sugar) Zymolyase-extracted material. The values shown correspond to the residual soluble antibody left behind and are the mean of at least three separate experiments, the standard deviation values of which were never higher than $10 \%$ of the mean.

were detected (Fig. 1). Laminarin did not affect the titre of the $\mathrm{mAb}$, regardless of how high the concentrations used in the pre-incubation were.

\section{Fractionation of mannan in a ConA-Sepharose column}

To study the relationships of $(1,6)-\beta$-glucan and mannan, mannan from $C$. albicans cell walls was passed through a ConA-Sepharose column and two fractions, corresponding to non-retained material $17 \%$ of the original carbohydrate) and to material retained and eluted by addition of methyl $\alpha$-D-mannopyranoside ( $85 \%$ of the original carbohydrate), were obtained. The carbohydrate content of the fractions was determined and equivalent amounts were analysed by ELISA using the mAb JRR1. The nonretained material, which contained only $17 \%$ of the original carbohydrate, nevertheless exhibited three times more immunoreactivity against the mAb JRR 1 than the retained material $\left(A_{405}=1 \cdot 25\right.$ vs $\left.A_{405}=0.40\right)$. Analysis by paper chromatography of the total acid hydrolysate of the retained material showed it to consist mainly of mannose and of a small amount of glucose, whilst partial hydrolysis also revealed the presence of gentiobiose (6-O$\beta$-D-glucopyranosyl-D-glucose), a $(1,6)-\beta$-disaccharide. These results show the existence of $(1,6)-\beta$-glucan that is covalently bound to mannan and is consequently retained by the ConA-Sepharose. Total and partial acid hydrolysis of the non-retained material showed that it consisted mainly of glucose and gentiobiose, respectively.

\section{Fractionation of Zymolyase-extracted material in a ConA-Sepharose column}

In order to test the possible existence of bonds between the glucan epitope recognized by the mAb JRR1 and the protein moiety of cell wall mannoproteins, mannoproteins released by Zymolyase from $C$. albicans yeast cell walls 
were passed through a ConA-Sepharose column. In this case the JRR1-epitope-containing material, as detected by ELISA, was mostly retained by the column $\left(A_{405}=1.36\right.$ vs $A_{405}=0 \cdot 46$ ), indicating that the epitope was bound to cell wall mannoproteins. The material retained and eluted with methyl $\alpha$-D-mannopyranoside was dialysed, lyophilized, dissolved in $2 \mathrm{M} \mathrm{NaOH}$ and heated at $100^{\circ} \mathrm{C}$ for $2 \mathrm{~h}$ to degrade the protein moiety of mannoproteins. The aim of this treatment was to release the oligosaccharides and possible glucan chains that were directly bound to amino acids in the mannoproteins. After neutralizing and diluting with Con $A$ buffer, the sample was passed again through the ConA-Sepharose column, and the presence of the JRR1 epitope in the retained and non-retained fractions was determined by ELISA. The result showed that after degradation of the protein moiety, an important percentage of the JRR1 epitope was no longer retained by the column $\left(A_{405}=1.22\right.$ vs $\left.A_{405}=0.61\right)$, pointing to the possibility that it was bound either directly to amino acids in the mannoproteins or through O-linked oligomannosides (see later). The remaining JRR1 epitope that was still retained by the ConA column might represent an epitope that is bound to the mannan moiety of mannoproteins, as has been shown above, and whose retention by ConA is not affected by the degradation of the protein moiety of mannoproteins.

\section{MAb JRR1 does not react with the mannoproteins secreted by regenerating spheroplasts}

In an attempt to determine whether $(1,6)$ - $\beta$-glucan is added to mannoproteins during their synthesis or after their secretion to the periplasmic space and incorporation to the extending wall, microtitre plates were coated with mannan preparations obtained either from the mannoproteins secreted by spheroplasts, or from isolated walls of yeast and mycelial cells of $C$. albicans. The results showed that the mAb JRR1 reacted with the mannan preparations obtained from the cell walls of either yeast $\left(A_{405}=1.37\right)$ or mycelial $\left(A_{405}=0.73\right)$ cells, indicating that they carried the corresponding epitope. On the other hand, mAb JRR1 did not react with the mannan preparations obtained from the mannoproteins secreted by regenerating spheroplasts after $6 \mathrm{~h}\left(A_{405}=0 \cdot 11\right)$.

\section{The JRR1 antigen is located in an inner layer of the cell wall}

The location of the antigen recognized by mAb JRR1 on the cell wall of $C$. albicans was determined by indirect immunofluorescence of cells growing either normally or in the presence of tunicamycin, an inhibitor of $N$ glycosylation of proteins.

Control cells were not labelled by the antibody (data not shown). Conversely, cells that had been incubated with tunicamycin were labelled, but the labelling was found only on the areas of the cell wall that had presumably been synthesized in the presence of the antibiotic (i.e. buds in the yeast form and apical tips in the mycelial form) (Fig. 2) and, as a consequence, their proteins were devoid of the mannan moieties.

\section{DISCUSSION}

The nature of the epitope recognized by the mAb JRR1 was deduced from the fact that pustulan, a $(1,6)-\beta$-glucan polymer, competitively inhibits the binding of the $\mathrm{mAb}$ to material containing a JRR1 epitope. The isolation of a $\mathrm{mAb}$ against $(1,6)-\beta$-glucan, a material that is not immunogenic by itself, can be explained by the use of Zymolyase extracts, in which short $(1,6)-\beta$-glucan chains may still remain attached to mannoproteins, as antigens.

An obvious application of the mAb JRR1 is the study of the relationships between mannoproteins and glucan. A direct linkage between $(1,6)-\beta$-glucan and chitin has been reported by Surarit et al. (1988) and between glucan and mannan by Van Rinsum et al. (1991), both in S. cerevisiae. Direct linkages between glucan and the protein moiety have been described in halobacteria (Wieland $e t$ al., 1983), in Prototheca ropfii (Rivas \& Pont-Lezica, 1987), and also recently in S. cerevisiae (Montijn et al., 1994).

In the present study, existence of linkages between the glucan-epitope recognized by the mAb JRR1 and the mannan moiety of mannoproteins was studied in ConASepharose-retained mannan from $C$. albicans yeast cell walls. ConA specifically binds materials that contain $\alpha$ mannose or $\alpha$-glucose residues, which can then be released by competition with methyl $\alpha$-D-mannopyranoside (Goldstein et al., 1965). The JRR1 epitope is present in the retained fraction, and this fact, together with the data on the composition of this material, as determined by acid hydrolysis and paper chromatography, showing that it includes both mannose and glucose, support the existence of direct links between the mannan moiety of mannoproteins and glucan in the cell walls of $C$. albicans.

The existence of direct linkages between the $(1,6)-\beta$ glucan epitope recognized by the mAb JRR1 and the protein moiety of mannoproteins was investigated using the Zymolyase extract from C. albicans yeast cell walls. The cell wall mannoproteins in the extract were purified by a first round of ConA-Sepharose chromatography and, after degradation of the protein moiety, the resulting material was submitted to a second round of ConASepharose chromatography, and both retained and nonretained fractions were obtained. After the first chromatography most of the JRR1 epitope was in the retained fraction, that is, bound to the intact mannoproteins. Following the degradation of the protein moiety the behaviour of the epitope changed and became, in a high percentage, non-retainable by the Con $\mathrm{A}$, indicating the possibility of a direct linkage to the protein moiety of cell wall mannoproteins.

Alternatively, two other explanations can be offered for this result. The first one would be the existence of a linkage between $(1,6)-\beta$-glucan and the terminal mannose of the $O$-linked oligomannosides of mannoproteins. This glucan-oligomannoside would be released after the degradation of the protein moiety of mannoproteins, and it would not be retained by the ConA because of the interaction between Con $\mathrm{A}$ and the oligomannoside being hampered by the presence of the $(1,6)-\beta$-glucan. This 

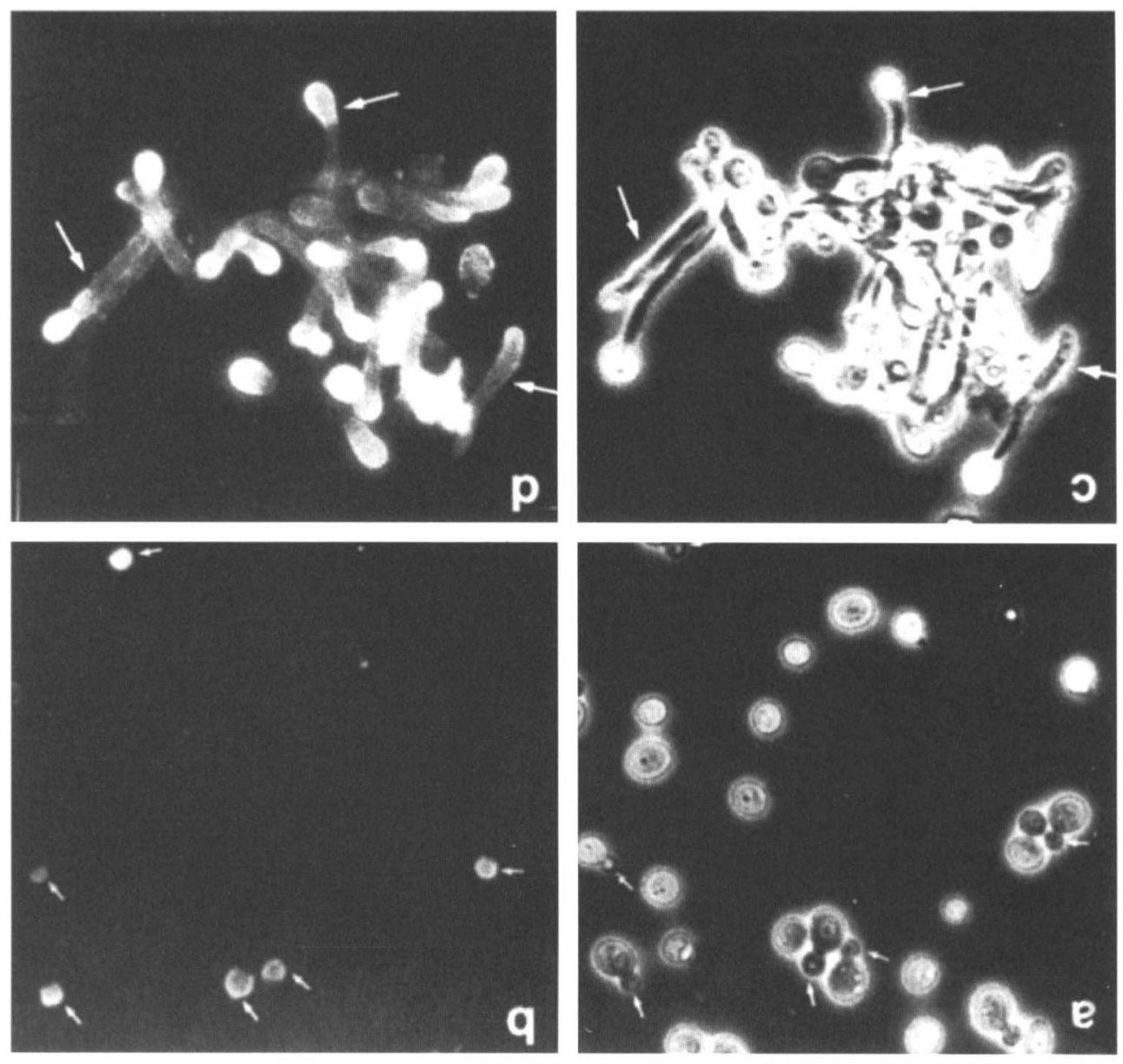

Fig. 2. Analysis by immunofluorescence of the distribution of the JRR1 epitope on the surface of $C$. albicans yeast (a, b) and mycelial $(c, d)$ cells grown in the presence of tunicamycin. $(a, c)$ Phase contrast micrographs; $(b$, d) fluorescence micrographs. Arrows point to fluorescent surfaces.

interpretation of our results would be in agreement with the fact that a mutant of $S$. cerevisiae (kre2), resistant to the killer toxin $\mathrm{k} 1$, is defective in the elongation of $\mathrm{O}$ linked oligomannobiose (Hill et al., 1992; Haüsler et al., 1992). As $(1,6)-\beta$-glucan is the receptor for the killer toxin, the defect in $O$-linked oligomannoside completion would prevent the attachment of $(1,6)-\beta$-glucan to the mannoprotein and hence prevent the formation of the $k 1$ receptor. The second explanation would be the existence, as has been recently suggested by de Nobel \& Lipke (1994), of a direct linkage between the C-terminal glycan (derived from a glycosyl-phosphatidyl-inositol anchor) from a mannoprotein and $(1,6)-\beta$-glucan. In this case, the degradation of the protein moiety would equally lead to the non-retention of the epitope by the ConA-Sepharose column.

Meaden et al. (1990) and Roemer et al. (1993), using a genetic approach in S. cerevisiae, have shown that synthesis of $(1,6)-\beta$-glucan begins early in the secretory pathway; accordingly it would be reasonable to assume that cell wall mannoproteins, as secreted by regenerating spheroplasts, would contain $(1,6)-\beta$-glucan residues. Neverthe- less, our results show otherwise, since the $\mathrm{mAb}$ reacted neither with mannoproteins secreted by regenerating spheroplasts, nor with mannan obtained from secreted mannoproteins. This indicates that either $(1,6)-\beta$-glucan is incorporated at a later stage, or that mannoproteins that contain this epitope are only secreted if there is a preformed cell wall structure to which they are directly incorporated.

Finally, the topology of the distribution of $(1,6)-\beta$-glucan was studied by indirect immunofluorescence, and the results confirm previous reports indicating that it is located within an inner layer of the cell wall (Kopecká et al., 1974) which is not accessible unless the outer layer, being formed by mannoproteins (Horisberger \& Vonlanthen, 1977; Koch \& Rademacher, 1980), is disturbed by the effect of tunicamycin.

\section{ACKNOWLEDGEMENTS}

We thank Jacqueline Perez and Carlos Peñarroja for their contribution in the production of monoclonal antibodies, and Hortensia Rico for her help with immunofluorescence. Raquel Sanjuán was supported by a grant 
from the Conselleria de Educació y Ciència de la Generalitat de València. This work was supported by grants from the Dirección General de Investigación Científica y Técnica (PB90-0424) and the Commission of the European Communities (EC Group on Candida albicans Cell Biology and Pathogenicity and $\mathrm{Cl} 1 * .0631 . \mathrm{M})$.

\section{REFERENCES}

Ballou, C. E. (1990). Isolation, characterization, and properties of Saccharomyces cerevisiae mnn mutants with non-conditional protein glycosylation defects. Methods Enzymol 185, 440-470.

Calderone, R. A. \& Braun, P. C. (1991). Adherence and receptor relationships of Candida albicans. Microbiol Rev 55, 1-20.

Casanova, M., Gil, M. L., Cardeñoso, L., Martinez, J. P. \& Sentandreu, R. (1989). Identification of wall specific antigens synthesized during germ tube formation by Candida albicans. Infect Immun 57, 262-271.

Chen-Wu, J. L., Zwicker, J., Bowen, A. R. \& Robbins, P. W. (1992). Expression of chitin synthase genes during yeast and hyphae growth phases of Candida albicans. J Mol Biol 6, 497-509.

Dubois, M., Gilles, K. A., Hamilton, J. K., Rebers, P. A. \& Smith, F. (1956). Colorimetric method for determination of sugars and related substances. Anal Chem 28, 350-356.

Edwards, T. E. (1965). Isolation of glycogen, glucan, and mannan polysaccharides from baker's yeast. Methods Carbohydr Chem 5, 176-179.

Elorza, M. V., Rico, H. \& Sentandreu, R. (1983). Calcofluor white alters the assembly of chitin fibrils in Saccharomyces cerevisiae and Candida albicans cells. J Gen Microbiol 129, 1577-1582.

Elorza, M. V., Murgui, A. \& Sentandreu, R. (1985). Dimorphism in Candida albicans: contribution of mannoproteins to the architecture of yeast and mycelial cell walls. J Gen Microbiol 131, 2209-2216.

Elorza, M. V., Mormeneo, S., Garcla de la Cruz, F., Gimeno, C. \& Sentandreu, R. (1989). Evidence for the formation of covalent bonds between macromolecules in the domain of the walls of Candida albicans mycelial cells. Biochem Biopbys Res Commun 162, 1118-1121.

Galfre, G. \& Milstein, C. (1981). Preparation of monoclonal antibodies: strategies and procedures. Methods Enzymol 73, 3-46.

Goldstein, I. J., Hollerman, C. E. \& Smith, E. E. (1965). Proteincarbohydrate interaction. II. Inhibition studies on the interaction of concanavalin A with polysaccharides. Biochemistry 9, 876-883.

Haúsler, A., Ballou, L., Ballou, C. E. \& Robbins, P. W. (1992). Yeast glycoprotein biosynthesis: $M N T 1$ encodes an $\alpha$-1,2-mannosyltransferase involved in O-glycosylation. Proc Natl Acad Sci US $A$ 89, 6846-6850.

Hill, K., Boone, C., Goebl, M., Puccia, R., Scidu, A. M. \& Bussey, H. (1992). Yeast $K R E 2$ defines a new gene family encoding probable secretory proteins, and is required for the correct $\mathrm{N}$-glycosylation of proteins. Genetics 130, 273-283.

Hoogenraad, N. J. \& Wraight, C. J. (1986). The effect of pristane on ascites tumor formation and monoclonal antibody production. Methods Enzymol 121, 375-381.

Horisberger, M. \& Rouvet-Vauthey, J. (1985). Cell wall architecture of the fission yeast Schizosaccharomyces pombe. Experientia 41, 748-750.

Horisberger, M. \& Vonlanthen, M. (1977). Localization of mannan and chitin in thin sections of budding yeast with gold markers. Arch Microbiol 115, 1-7.
Klis, F. M. (1994). Review: cell wall assembly in yeast. Yeast 10, 851-869.

Koch, Y. \& Rademacher, K. H. (1980). Chemical and enzymatic changes in the cell walls of Candida albicans and Saccharomyces cerevisiae by scanning electron microscopy. Can J Microbiol 26, 965-970.

Kopecká, M., Phaff, H. J. \& Fleet, G. H. (1974). Demonstration of a fibrillar component in the cell wall of the yeast Saccbaromyces cerevisiae and its chemical nature. J Cell Biol 62, 66-72.

Lee, K., Buckley, H. R. \& Campbell, C. C. (1975). An aminoacid liquid synthetic medium for the development of mycelial and yeast forms of Candida albicans. Sabouraudia 13, 148-153.

Lindberg, B. \& McPherson, J. (1954). Studies on the chemistry of lichens. VI. The structure of pustulan. Acta Chem Scand 8, 985-991.

Marcilla, A., Elorza, M. V., Mormeneo, S., Rico, H. \& Sentandreu, R. (1991). Candida albicans mycelial wall structure: supramolecular complexes released by zymolyase, chitinase and $\beta$-mercaptoethanol. Arch Microbiol 155, 312-319.

Marcilla, A., Mormeneo, S., Elorza, M. V., Manclús, J. J. \& Sentandreu, R. (1993). Wall formation by Candida albicans yeast cells: synthesis, secretion and incorporation of two types of mannoproteins. J Gen Microbiol 139, 2985-2993.

Meaden, P., Hill, K., Wagner, J., Slipetz, D., Sommer, S. S. \& Bussey, H. (1990). The yeast $K R E 5$ gene encodes a probable endoplasmic reticulum protein required for (1-6)- $\beta$-glucan synthase and normal cell growth. Mol Cell Biol 10, 3013-3019.

Montijn, R. C., Van Rinsum, J., Van Schagen, F. A. \& Klis, F. M. (1994). Glucomannoproteins in the cell wall of Saccharomyces cerevisiae contain a novel type of carbohydrate side chain.J Biol Chem 269, 19338-19342.

de Nobel, H. \& Lipke, P. N. (1994). Is there a role for GPIs in yeast cell-wall assembly? Trends Cell Biol 4, 42-45.

Reese, E. T., Parrish, F. W. \& Mandels, M. (1962). $\beta$-D- $(1,6)$ Glucanases in fungi. Can J Microbiol 8, 327-334.

Rivas, L. A. \& Pont-Lezica, R. (1987). Synthesis of $\beta$-glucans in Prototheca zopfii. Evidence for the existence of a glycoprotein primer. Eur J Biochem 163, 129-134.

Roemer, T., Delaney, S. \& Bussey, H. (1993). SKRN1 and KRE6 define a pair of functional homologues encoding putative membrane proteins involved in $\beta$-glucan synthesis. Mol Cell Biol 13, 4039-4048.

Schekman, R. \& Novick, P. (1982). The secretory process and cell surface assembly. In The Molecular Biology of the Yeast Saccharomyces, pp. 361-398. Edited by J. N. Strathern, E. W. Jones \& J. R. Broach. Cold Spring Harbor, NY: Cold Spring Harbor Laboratory.

Schreuder, M. P., Brekelmans, S., Van den Ende, H. \& Klis, F. M. (1993). Targeting of a heterologous protein to the cell wall of Saccharomyces cerevisiae. Yeast 9, 399-409.

Shematek, E. M., Braatz, J. A. \& Cabib, E. (1980). Biosynthesis of the yeast cell wall. I. Preparation and properties of $\beta(1-3)$ glucan synthase. $J$ Biol Chem 255, 888-894.

Shepherd, M. G. \& Gopal, P. K. (1993). Nature and control of cell wall biosynthesis. In Dimorphic Fungi in Biology and Medicine, pp. 153-169. Edited by H. V. Bossche, F. C. Odds \& D. Kerridge. New York: Plenum Press.

Sonnenberg, A. S. M., Sietsma, J. M. \& Wessels, J. G. H. (1982). Biosynthesis of alkali-insoluble cell wall glucan in Schizophyllum commune protoplasts. J Gen Microbiol 128, 2667-2674.

Sundstrom, P. M., Nichols, E. J. \& Kenny, G. E. (1986). Antigenic differences between mannoproteins of germ tubes and blastospores of Candida albicans. Infect Immun 55, 616-620. 
Surarit, R., Gopal, P. K. \& Shepherd, M. (1988). Evidence for a glycosidic linkage between chitin and glucan in the cell wall of Candida albicans. J Gen Microbiol 134, 1723-1730.

Torosantucci, A., Boccanera, M., Casalinuovo, I., Pellegrini, G. \& Cassone, A. (1990). Differences in the antigenic expression of immunomodulatory mannoprotein constituents on yeast and mycelial forms of Candida albicans. J Gen Microbiol 136, 1421-1428.

Trinel, P. A., Faille, C., Jacquinot, P. M., Caillez, J.-C. \& Poulain, D. (1992). Mapping of Candida albicans oligomannosidic epitopes by using monoclonal antibodies. Infect Immun 60, 3845-3851.

Van Rinsum, J., Klis, F. M. \& Van den Ende, H. (1991). Cell wall mannoproteins of Saccharomyces cerevisiae mnn9. Yeast 7, 717-726.

Voller, A. \& Bidwell, D. (1986). Enzyme-linked immunoadsorbent assay. In Manual of Clinical Laboratory Immunology, pp. 359-371. Edited by M. R. Rose, H. Friedman \& J. L. Faehey. Washington, DC: American Society for Microbiology.

Wessels, J. G. H., Sietsma, J. H. \& Sonnenberg, A. S. M. (1983). Wall synthesis and assembly during hyphal morphogenesis in Scbizopbyllum commune. J Gen Microbiol 129, 1607-1612.

Wieland, F., Heitzer, R. \& Shaefer, W. (1983). Asparaginylglucose: novel type of carbohydrate linkage. Proc Natl Acad Sci US A 80, $5470-5474$.

Received 22 November 1994; revised 21 February 1995; accepted 23 March 1995. 